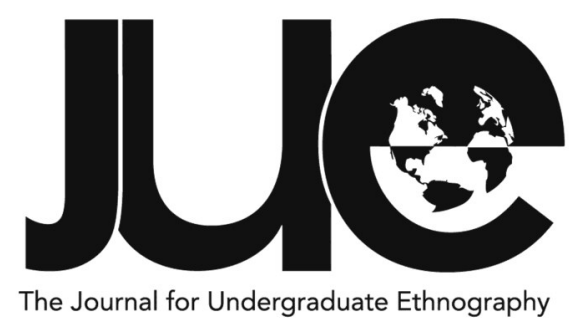

\title{
Implementation of Personalized Learning in a New Charter School
}

\author{
Emily Cowart \\ Presbyterian College, ejcowart@presby.edu
}

\section{ABSTRACT}

Personalized Learning (PL) is an educational approach that tailors instruction to the academic needs of each student. Most research on PL focuses on student achievement, technology, and implementation challenges. Little research has been conducted on the actual practices that teachers use to personalize instruction and on students' and teachers' feelings about being in a school that implements PL. I conducted a case study at a recently opened rural elementary charter school in the southern United States, which was implementing PL schoolwide. After attending a professional development workshop on PL hosted by the State Department of Education, I conducted classroom observations in a first-grade and a fifth/sixth-grade classroom. I interviewed the teachers of these classes, the school principal, and three students. Three themes emerged from my analysis of this material, relating to student engagement, teacher behaviors and dispositions, and student outcomes. Overall, I concluded that PL is not a quick or easy transition for a school to make, nor does it involve just changing the curriculum to individualize instruction for students. Personalized Learning requires an adaption of teacher and student mindsets and the development of a school culture that fosters both academic and social-emotional growth among the students. 
A $\mathrm{n}$ approach to teaching and learning that has increased in popularity in recent years is Personalized Learning, in which students advance at their own pace, material is connected to students' interests and experiences, students have both choice and voice within the classroom, and assessments are designed to allow students to demonstrate their learning in a multitude of ways (Murphy, Redding, and Twyman 2016, 57-69).The South Carolina Department of Education (SCDE) established a Personalized Learning (PL) Department three years ago and is now working with 33 districts on implementing this approach. According to the PL Coach from the SCDE, the approach is popular because it gives students a sense of ownership, teaches them responsibility, and empowers them (Catto 2019).

Previous research focuses on the different elements that comprise $\mathrm{PL}$, but little research has been conducted on the practices that teachers use to personalize instruction and set goals for students in the classroom, or how students and teachers feel about being in a school that implements PL. Furthermore, there is virtually no research on why teachers choose to work at a school that implements this approach to learning and teaching. It is important to conduct further research to increase educators' knowledge about particular strategies, the challenges associated with $\mathrm{PL}$, and its benefits for students to fully understand all aspects of its implementation. I conducted a case study of a new school, Thomas Charter School (a pseudonym), which opened in August 2019 as a Personalized Learning school, in order to gather more information about PL from the perspectives of the administrator, teachers, and students. This research will enlighten educators and families on how PL works in practice and what benefits it can yield when effectively implemented.

\section{What is Personalized Learning?}

While Personalized Learning may be seen as a new approach, Campbell et al. (2007) argue that it is really just constructivist learning based on Vygotsky's social theory in which teachers scaffold instruction for students. They see PL as a collaborative activity between teachers and students, rather than individualized instruction for each student, which, they argue, can only be accomplished through one-on-one tutorials. Although PL can be implemented at all grade levels, Campbell et al. propose that because it involves teachers and students co-producing knowledge, the approach is more suited to older, high-achieving students who are capable of higher order thinking.

Regardless of the grade level in which it is implemented, Personalized Learning has several key features. The RAND Corporation (Pane et al. 2015, 3) report that incorporating separate time for individual student support is common in PL schools, as is allowing students to set their own learning goals (Pane et al. 2015, 50). In a study of middle school teachers' approaches to goal setting, De-Mink et al. (2017) identified a range of approaches to goalsetting among teachers, including: independent design, (b) interest-driven co-design, (c) interest and skill-driven co-design, (d) skill-driven co-design, and (e) selection. In the co-design approaches, the students and teachers collaborate to align their goals to different disciplinary skills. The researchers found that most of these approaches involved connecting learning to students' interests, students actively participating in the design of their learning, and students taking responsibility for their learning. These findings highlight the collaboration between teachers and students that PL fosters.

In order to determine the most common structural elements of Personalized Learning, Olofson et al. (2018) administered a survey to 308 teachers. The results indicated that the most common practices teachers used were whole-group learning, customized learning, personalized assessments, and technology implementation. Other research (for instance, 
DeMink-Carthew et al. 2017, 5-8; Schmid and Petko 2019, 79-80) also indicates that the most common structural elements include varied classroom models (customized, or whole-group/small-group where either the entire class is taught together or they are placed into small groups for instruction), technology implementation such as online delivery and digital tools, student choice/ interest, and personalized materials and classroom environments, which will be discussed in more detail in my study.

\section{Research on Personalized}

\section{Learning}

Existing research on Personalized Learning focuses on student achievement, the use of technology, and implementation challenges. In terms of the benefits of $\mathrm{PL}$, it has been found that personalizing not only units of instruction and materials for students but also the classroom environment and learning goals has a positive impact on student achievement. The RAND Corporation examined the ways teachers personalized learning and the effects it had on student achievement (Pane et al. 2015). The researchers conducted site visits, interviewed school administrators, reviewed teacher logs and surveys, administered surveys to teachers and students, and evaluated achievement data from 32 schools that did and did not implement Personalized Learning. They found that after being in a PL school for two years, students showed gains in both math and reading performance in comparison to their peers in non-PL schools. They found that flexible student groupings, learning spaces that supported the models of a personalized classroom, and students discussing data related to their personal learning goals contributed to student achievement (Pane et al. 2015).

Research also indicates positive effects of personalizing even one unit of study. Bernacki and Walkington (2018) personalized four units of algebra for 155 ninth-grade students to examine the impact on student performance and interest in the topic. To personalize the math, the researchers related problems to students' interests and their home or community backgrounds and interviewed students after each unit to assess their interest.
The results indicated that personalizing the units for students triggered greater interest in the subject matter and had positive effects on their achievement in classroom exams.

Technology is a common aspect of Personalized Learning implementation both within the United States and in other countries. Schmid and Petko (2019) administered an online survey to 860 eighth-grade students in 31 schools in Switzerland to determine whether the use of digital technologies for Personalized Learning helped students develop technological skills. The results showed that $86 \%$ of the students used a computer in class which shows a strong correlation between PL schools and the use of both technology and technological skills. In another study, the inclusion of technology was found to have a strong positive effect on both students' self-reported digital skills and their positive attitudes towards technology use in the classroom (Lee et al. 2018, 1270-1275).

Lee et al.'s research study (2018) also investigated teachers' technology use and needs in schools that were based on a framework of Personalized Integrated Education System (PIES), a course management system for recordkeeping, planning, and instruction in Personalized Learning schools. The researchers evaluated the survey responses of 245 teachers from 41 schools across the United States that were implementing Personalized Learning. They found that only $12 \%$ of teachers had a technology system that integrated the four major aspects of PIES and $21 \%$ reported they had no such technology system. Overall, the findings indicated that technology was typically used by teachers for recordkeeping, planning, instruction, and assessments. In a two-year study of 28 Personalized Learning schools, Bingham et al. (2018) conducted interviews, focus groups, observations, and surveys with teachers, administrators, and students to identify challenges, disruptions, and contradictions within schools. The results showed that teachers and administrators experienced similar challenges regarding a lack of available technology. Students reported issues with technology not working correctly or not having the technological skills needed for 
the amount of technology use within the classroom.

Although research indicates that Personalized Learning contributes to student achievement (Bernacki and Walkington 2018, 864; Pane et al. 2015, 10-17), challenges with technology, standardized testing, student choice, and teacher preparation can elicit issues for both teachers and students in PL environments. Available technology often does not align with teachers' needs and students often also experience technology issues. Bingham et al. (2018) identified issues that both teachers and students faced, including those associated with internet failure and the absence of backup lesson plan options, online content not aligning with personalized goals, and students not having the requisite digital skills.

In addition, research indicates that teachers experience many challenges in attempting to align their Personalized Learning methods to standardized testing. Results of the RAND Corporation study (Pane et al. 2015) show that teachers thought they should be teaching grade -level content aligned to standardized testing rather than having students working at their own pace. Expectations related to students' performance on standardized tests are a major challenge for both teachers and students in $\mathrm{PL}$ schools. In Bingham et al.'s two-year study on 28 schools, most teachers felt that their measurement of success did not align with the standardized tests that outside stakeholders used to evaluate students, and students felt distressed and unprepared for these tests.

Another common challenge that teachers and students face relates to the implementation of choice. Netcoh (2017) conducted 11 classroom observations, as well as individual interviews and focus groups with 80 middle-school students and teachers at a low-socioeconomic status (SES) and culturally mixed school in Vermont. He found that students and teachers struggled over the structure of choice and control within the class. The students often felt that they should have more unconstrained choices in their academic programs, yet the teachers wanted to be more involved to ensure academic rigor. In contrast, in Bingham and Dimandja's (2017) study, students often felt overwhelmed by the amount of choice they had, and at the same time, teachers struggled to structure learning environments and projects because the students had so much choice.

Teacher preparation and expertise are imperative for any classroom to run smoothly. Moreover, an improperly prepared teacher who is unsure of effective strategies to use in a Personalized Learning classroom can face numerous challenges (Bingham et al. 2018, 481482). In a three-year case study, Bingham and Dimandja (2017) examined teachers' experiences implementing $\mathrm{PL}$ at a low-SES charter high school. The researchers interviewed 17 teachers, six administrators, and the CEO of the charter school's management organization. They also observed teachers in their classrooms and evaluated artifacts such as the parent/student handbook, grant documents, and class websites. Overall, teachers reported that consistency in the use and evaluation of student data was key to effective instruction and student success. The most significant finding, however, was related to the length of time teachers had been in the field. Teachers who had fewer years of experience had different struggles with technology and the pressures of accountability than teachers with more experience. In particular, this study uncovered a disconnect between what preservice teachers were taught regarding the delivery of an exemplary lesson and the PL model of a lesson. Teachers in their first years of teaching were likely not only to set standards and goals, but also to dictate what each lesson would entail, what the students would be doing, what they learned, and how they would be assessed. In PL, however, students are supposed to have choices even to the extent of picking the standards they are working on, their learning goals and objectives, and the methods of assessing them.

Previous research has focused on student achievement, the use of technology, and challenges within Personalized Learning school environments. The main challenges that have been identified in the research relate to technology use, teacher preparation, student choice, measurement of student success, student accountability, and standardized testing. Notwithstanding these findings, 
research on $\mathrm{PL}$ is limited as it is still a relatively new approach. The research that I report in this article helps extend this body of research through a case study of a new school in its first year of implementing Personalized Learning.

\section{Methods}

Before beginning this study, I obtained approval from Presbyterian College's Institutional Review Board (IRB). I then obtained consent from the principal of the school, the two teachers of the classrooms in which I conducted my study, and, later, the students I interviewed as well as their parents/guardians.

I conducted this study on a school campus in a rural southern U.S. city. The school had been shut down in 2007 and reopened in 2019 as a charter school. Thomas Charter School currently serves 154 students from Kindergarten to sixth grade, with intentions of adding additional grade levels in the upcoming years. Of the 154 students who attend the school, 32\% are minorities (African American, Hispanic, and Mixed ethnicities) and 53\% receive either free or reduced-price lunch. There are 31 students who receive special education services and there are no students who are English Language Learners.

Before collecting data for my study, I attended a Personalized Learning professional development workshop facilitated by a trainer from The Ohio State University where I was able to interact with teachers and administrators from different school districts who were new to Personalized Learning. I also had the opportunity to informally interview the Personalized Learning Coach from the South Carolina Department of Education (SDCE) about different aspects of the Personalized Learning method and the districts the SCDE was currently working with.

My next step involved conducting classroom observations in two teachers' classrooms. I observed four hours in a first-grade classroom and seven hours in a fifth/sixth-grade Math and Science classroom. While observing, I took notes on the different aspects of Personalized Learning I saw being incorporated in the classroom, based on my review of literature and components described in the Professional Development workshop.
I then conducted interviews with six participants: the school principal, two classroom teachers, and three students (to whom I refer by pseudonyms in this article). The principal, Dr. Watson, had been a principal for 10 years, but this was his first year at Thomas Charter School. Mrs. Caldwell was a first-grade teacher who had been teaching for nine years, mostly as a Montessori teacher. Mrs. Mason was the fifth/sixth-grade Math/ Science teacher and she had been teaching for 16 years. She recommended the three students (two in sixth grade and one in fifth grade) that I interviewed. Two of the students were White and the third was African American. Two students were male and one was female. The students varied in academic ability and had attended different schools previously. The teacher recommended these three students not only because of the diversity they represented in terms of their gender, race, and academic abilities, but also because they were vocal students who had demonstrated an ability to articulate their opinions in the classroom.

The interviews and the observations took place during the 80 hours I spent at Thomas Charter School as part of one of the field experience requirements for my preservice education program. I created three different interview guides for the principal, teachers, and students, basing my questions on previous research findings, the professional development workshop, and my classroom observations. Each audio-recorded interview lasted around 30 minutes. I transcribed the interviews verbatim within two days of conducting the interviews. In order to identify common themes among the participants, I read through all transcripts as a whole using a system of open coding described by Creswell and Poth (2018). For example, the students, teachers, and principal all referenced students' "motivation" and "choice." I combined these codes, and others, such as "ownership" and "student interests," to create the theme of "student engagement."

One way that researchers can increase the validity of their findings in qualitative research is through data triangulation (Denzin and Lincoln, 2011). In this study, I used multiple 
sources of data including observations, interviews, and a literature review to corroborate my findings. In this way, I was able to triangulate my findings. For example, I corroborated the information that teachers, students, and the principal shared with me through their interviews by conducting classroom observations. Moreover, through the interviews I was also able to find support for the information provided at the professional development workshop I attended on Personalized Learning. For instance, one of the benefits presented at this workshop was the use of student choice. In the interviews, teachers provided specific examples of how the choices they gave students were beneficial and conducive to learning. Through my classroom observations, I was able to confirm this information by seeing the scope of choices students were given and students' engagement while learning.

Acknowledging the researcher's perspective, experience, and biases can help to increase the credibility of qualitative analysis (Patton, 1990). Therefore, it is important for me to acknowledge the shift in my thinking about Personalized Learning throughout the research process. As a preservice teacher candidate, I had minimal teaching experience. My firsthand experience with Personalized Learning occurred during 80 hours of practicum fieldwork at Thomas Charter School, during which time I conducted this study. Subsequently, I completed a 15-week student teaching experience in the same classroom at Thomas Charter School, providing me greater insight into the practice of Personalized Learning and allowing my position to shift. When Personalized Learning was first explained to me prior to my field experience, I believed it to be an exceptional idea but was highly skeptical of how it would realistically work within a classroom. I saw the benefits of meeting students where they were academically; however, due to the difficulties I envisioned of individualizing instruction and fostering student ownership of learning, I was hesitant to trust that the approach would be beneficial for all students and teachers. Initially, I thought it involved teaching each student at the academic level they were on, rather than the grade level they were in, which I did not think would be feasible.

However, as I spent time in the field and got to witness students' academic growth, I recognized that my initial conceptualization of Personalized Learning was inaccurate. Students were, in fact, taught material based on the grade level they were in. However, the teacher used specific methods to make the work manageable for students who were academically below grade level, such as presenting the content in smaller chunks and decreasing the quantity of work they had to do. These modifications allowed students to progress at their own pace on grade-level standards. I witnessed students whose academic growth increased by more than two grade levels in one academic year. Therefore, my initial skepticism about Personalized Learning gradually faded throughout my time in the field. I saw not only how it was implemented in a way that was manageable for the teacher, but also how students benefited from the individualized approach.

\section{Participants' Previous School Experiences}

Participants' previous experiences of school clearly influenced how they experienced and felt about Personalized Learning. Each of the students interviewed went to a different school before coming to Thomas Charter School, yet they all reported similar experiences with bullying, academic achievement, and ineffective teachers. Bryan, in particular, noted that there was one "mean kid" in his class who constantly caused problems for him, yet the teachers' discipline was not effective in stopping the behavior. He shared that he was often bullied and made fun of at his old school for not being able to read as well as other students. Similarly, Dedrick claimed that his peers would "smack talk" him and were rarely kind to him. Lauren also experienced bullying and witnessed many fights at her old school. Each of these students said that the teachers and principals were strict, yet not consistent or effective with their disciplining of students, so the bullying would always continue. The students also told me that learning at their old school was not enjoyable. They said that they rarely used technology, test- 
taking was never fun, the academic objectives were too hard, and all students got the same work. Moreover, teachers would not provide as much help as they needed when they were struggling. These students all stated that they did not like and did not want to attend their old schools, in contrast to how they felt now with regards to Thomas Charter School. It should be noted that due to students' previous negative school experiences, their fondness for Thomas Charter School may not have been as much a result of the Personalized Learning approach itself, as of the sense of community promoted by teachers who appeared to be genuinely invested in their learning.

The two teachers I interviewed had different experiences of, yet similar beliefs about Personalized Learning. For instance, the 1st-grade teacher claimed that her background as a Montessori teacher for three different grade levels was well-suited to the Personalized Learning approach. In contrast, the fifth/sixthgrade teacher claimed that at her previous school she was not allowed to "follow the child" as required in Montessori and Personalized Learning; in fact, she felt that she could not devote time to students who were struggling in her classroom. Although both teachers had different prior background experience as teachers, they both fully supported the idea of Personalized Learning to help students reach or exceed the expectations associated with the grade level they were in.

The principal, Dr. Watson, had worked in education for 21 years, serving as a principal for nine years and an assistant principal for three years prior to that. This was his tenth year as a principal and his first year at Thomas Charter School and his first year implementing a Personalized Learning approach. Dr. Watson's prior schools were low-income with a high population of the students below-grade level. It is likely that his experience with needing to meet so many students at their own academic level at his previous schools led him to take a central role in implementing Personalized Learning as a school-wide approach.

In my analysis of interview transcripts, three key themes emerged in relation to the research participants' practices and experiences of PL: student engagement, teacher behaviors and dispositions, and student outcomes.

\section{Student Engagement}

When I asked the principal how he made hiring decisions about teachers, he responded:

One of the things I believe in is, one of the most powerful things is, you can't have personalized learning without student engagement and student engagement is a very, very important part of our school. If you don't have student engagement you don't have learning and you don't have skill development. Students have got to learn how to have fun, so one of the things we did, I asked teachers, asked all candidates to submit a three-minute video and they had to discuss why they became a teacher, what student engagement meant to them, and how they could implement personalized learning in the classroom.

Both the students and teachers indicated that one of the biggest ways that teachers engaged students in learning was through choice. The first-grade teacher, Mrs. Caldwell, discussed how she had transitioned from whole-group learning at the beginning of the year to "station rotation" where the students were split into groups and rotated around the room to complete different activities selected from choice boards (graphic organizers that presented options for how students could learn a concept). For example, students could choose the order of the lessons they completed or the activities they completed. In addition, she personalized the choice boards by giving fewer choices to students who had difficulty choosing from too many options. She noted that students were a lot more focused and got more accomplished since she had begun implementing the choice boards.

The fifth/sixth-grade teacher, Mrs. Mason, used choice in a similar way. Her students were given choice boards and were allowed to choose their "learning pathways," which was the way they chose to learn a particular unit or standard. Unlike Mrs. Caldwell, Mrs. Mason faced challenges because all of her students were in their first year at Thomas Charter School, and as they had transferred from traditional schools, they were not used to taking 
control of their learning. Mrs. Mason found herself having to coach students to help them understand why they needed to challenge themselves and how they would grow because of their choices. She stated that the most effective method was to use "baby-steps" in modeling how to make choices.

Along with the Personalized Learning concept of choice comes a great deal of accountability. Students discussed how they set academic goals with the guidance of their teachers, then monitored the completion of their goals, and shared their progress with their teachers. This process allowed students to gain a sense of ownership over their learning. Bryan explained that students were supposed to "teach themselves" and help each other while working in groups, which enabled them to take responsibility for their learning.

Reflecting on the sense of ownership that students displayed in the classroom, Mrs. Caldwell stated, "I think it is that ownership that they have and what they're choosing to do and it just makes it a better experience for them - that's what I've seen with the transition in just these 14 weeks, they are happier and better-working kids." The three students also noted that they liked learning this way. Dedrick enjoyed the challenge because he could be pushed to learn at a higher grade-level than he was currently in. Lauren said that she appreciated the amount of coaching and guidance the teachers provided and the way they incorporated fun activities into learning:

The way Miss Mason teaches math is like, whenever we take tests it's kind of online and how she has, like, you'll do something kind of non-fun and then you kind of do something fun after it. I kinda like that and I kinda like how she'll tie something fun in with it to keep us occupied, like a lot of times we'll take tests on Prodigy [an online game-based math program] and I like it because you're having fun battling the monsters but you're doing the questions anyway.

In sum, the students noticed that teachers were making an effort to engage them in learning, and from the teachers' perspectives, student engagement was central to both the functioning of the classroom and student achievement.

\section{Teacher Behaviors and Dispositions}

All teachers at Thomas Charter School had to learn about, and adapt to, the Personalized Learning approach. The teachers were trained in $\mathrm{PL}$ for 40 hours over the summer prior to school starting. A central component of $\mathrm{PL}$ involves teachers making the effort to tailor instruction to students' different levels in the class. Dedrick said that teachers individualized quizzes and gave students different work to see what students had mastered and what they were capable of. He also explained that teachers paid attention to each student's needs and tried to get them on grade level if they were below the required standards. Lauren described how teachers went around the room assisting students and described $\mathrm{PL}$ in the following way:

It is like when people have different abilities, like some people run fast and some people run slow, some people run in completely different ways, if you run in completely different ways, Miss Mason and Miss Harrison will give out different work or help people in different ways.

As a teacher, Mrs. Caldwell's view of PL supported Lauren's definition by incorporating her commitment to teaching a student no matter how long it took. Mrs. Mason expressed the importance of meeting students at their level to build a foundation of knowledge before they could meet the standards that the state required of them. She stated that her focus was coaching students to keep meeting higher goals so that they would be ready to earn the credits they need to graduate from high school.

Both teachers used short whole-group instruction and choice boards and worked with students in groups to implement Personalized Learning. They used the data they gained from their assessments to tailor the work for students' individual needs. They took the time to plan their groupings based on students' different ability levels. For station rotations, the teachers normally grouped students by similar achievement levels, but if they were learning a new topic, they made sure that there was at least one higher-level student in each group. The teachers also worked individually with 
students to get them on their age-related grade level. The extra time and effort it took to individualize work to this extent demonstrated that the teachers were committed to helping students make progress towards increasingly higher goals.

Both Mrs. Caldwell and Mrs. Mason commented that in a Personalized Learning school, students were not viewed as a number as they were in other schools. Mrs. Caldwell described the appeal for parents of Thomas Charter School in the following way:

I know our schools aren't huge around here but they're still very large and the way our education accountability system is set up, it's a big numbers game, and so I feel like the stress put on students and teachers is significant, and I think an opportunity to come where the atmosphere is smaller, so it's more of a community, and your child is seen, like seen as a child and not a number or score or another one to get through... I don't think that all of them [parents] truly understand it [Personalized Learning] but I think that they know it's a good thing for their child because it tailors the learning experience for their child. And some students who come here have had a hard time keeping up with the pace that's been given to them in previous years, and some students are ready to go above and beyond that, and so I think just the opportunity to meet with a child's needs is a big draw-in for parents.

Mrs. Caldwell suggested that the reason parents chose to send their child to Thomas Charter School was because it was a smaller school where students would not only be given more individual attention but would be viewed in an entirely different way. She explained that instead of each child just being another student that passes through the teacher's class, they are given the ability to move at a pace that works for them, whether that be going slower and getting extra help, or moving ahead to challenge themselves more.

\section{Student Outcomes}

The happiness and pride students felt in themselves and their academic achievements appeared to be the most significant student outcome of Personalized Learning. All three students claimed that the way they learned at Thomas Charter School was more enjoyable than at their previous schools, especially due to the greater amount of group work that they were given. The students also appreciated having peers who were willing to help each other and not bully one another. Lauren specifically liked that each student was able to get what they wanted out of a lesson because the teachers at Thomas Charter School attempted to include fun in their learning.

Mrs. Mason discussed several instances where she saw how much students enjoyed school because of the sense of community that had been developed. She described how students had developed new attitudes towards school:

The difference I've seen is the kids want to come to school now when they used to not care about coming to school. We had a student whose dad picked them up early and he cried because he didn't want to leave, so I was like, 'oh my gosh, his dad is here and he's crying - what's wrong? This is going to be terrible,' and he was like, 'I don't want to leave,' and I was like, 'wait, dad is picking you up to go get food,' and he was like, 'I don't want to leave because we had a house [classroom] party.' I mean it is very motivating and encouraging and engaging. It's a cool place to be if you're a kid, I mean it's fun.

Mrs. Mason relayed this incident as an example of how students felt about the PL environment at Thomas Charter School. There was a sense of community that helped students feel part of their school in a way they had not felt in their previous schools. To a large extent, this community was established through the PL practices that helped students feel confident about themselves and their abilities. For example, Mrs. Mason used a computer program to have the students work on different tasks. If they were struggling, the program would give them the names of three different students who had already mastered that concept. The program randomly picks the three names and does not necessarily pick the highest-level students. Mrs. Mason described a particular situation in which a student who was 
typically on the higher end of the academic spectrum, asked another student, Bryan, who was on the lower end, for help. The other students, including the student who asked Bryan for help, gave Bryan compliments on his work. Bryan was very excited to be in this position as he was not used to being considered "smart." Mrs. Mason described how Bryan became highly motivated in his work after this exchange. In other words, the positive environment that Thomas Charter School had established fostered confidence in students and enthusiasm for learning. When discussing changes in the students since being at Thomas, the principal exclaimed, "I mean it's amazing - we have kids that love school, want to be at school that have never in their life ever wanted to go to school."

Student outcomes also came in the measurable form of academic progress and grades. For instance, Lauren explained that at her old school, her lowest grade was in Social Studies, and now, it was one of her highest grades. Moreover, Mrs. Mason described a student who started the year on a first-grade level and was now on a third-grade level. She felt that if she had students gaining two years in her class, she would be able to eventually fill their academic gaps and get them up to their grade level. Mrs. Mason also stated that although long-term achievements were difficult to see now, she predicted significant achievements for students in the future:

I think the school has to implement it for a long time before you see the major achievements. ... I want to see these firstgraders all the way through sixth grade and I think the achievement is going to be amazing... I have seen within my class, I've seen more students proud of themselves than they've ever been and making their own goals.

Mrs. Mason had noted immediate improvement in student achievement, especially in regards to how the students felt about their academic performance and gaining a sense of ownership. She also predicted that while it may take time to develop, PL would get these students up to grade level, and that significant achievements would be apparent in the future. When I asked the principal how PL may be beneficial for students after they graduate, he stated that companies believe in the concept of $\mathrm{PL}$ and have put money into this new trend because it fosters ownership and allows students to reach their full potential. Furthermore, he claimed that companies will be more inclined to support this method of education in the future, stating:

I think Personalized Learning is a new trend and the new way because it shows more productivity in learning and making the grade and also developing a product in a lot of companies. The Bill and Melinda Gates Foundation supports Personalized Learning, a lot of Fortune 500 companies are big on Personalized Learning because they've seen the impact that it has on them [students].

Based on research that he had conducted, the principal claimed that students who attend Personalized Learning schools will be more prepared for the work world in the future. He predicted that because major companies are supporting this approach and want to employ people who have a sense of ownership in their work, Personalized Learning will become a growing trend within schools.

\section{Teacher and Student Perspectives of PL Strengths and Weaknesses}

One of the most significant implications of this study into Personalized Learning in a new school is that the whole culture of the school needs to adapt to this approach. Teachers must adopt a new mindset about teaching and learning and must be willing to help each student by creating a supportive and caring classroom environment. Mrs. Mason, whose son attended Thomas Charter School, described the culture of the school from the perspective of a teacher and a parent:

It's such a loving culture, like welcoming, you know what I'm saying? It just feels I don't know, it's comfort, it's comfort, I feel safe bringing my child here every day, like I know he's loved every single day in this building. He's not just a number, he's not gonna be forgotten about, even though he's not the greatest student he's not gonna be overlooked - he's going to be taken care of. So I think we have, especially sixth grade, we have a huge opposite spectrum - we have 
some that are super, super high and we have some that are really, really low, so I think both sets of parents want their child challenged or want their child cared for. Like, do something for my child - just don't leave them behind, do something for my child but don't let them sit there bored.

Mrs. Mason passionately described her love of the culture that had developed, which fostered love and support for her child. Moreover, she stated that Personalized Learning met parents' desire to have their children, no matter their level of academic achievement, be supported and challenged at school. Mrs. Mason gave an example of the impact of the school's culture she had seen on a child. One of her students, who had never enjoyed or been very good at math, was now excited and making gains in his work. He even commented to her about how nice it felt to have teachers that cared about him and cared about helping him succeed in math.

Both Mrs. Caldwell and Mrs. Mason modified the amount of work for specific students according to their ability levels. Mrs. Mason explained that she liked having flexible groups so that she could move students to different groups based on the unit, lesson, or task they were completing that day. The everchanging groups showed students that while one student may have already mastered a certain skill when they had not, the following week, they may be the one who had mastered a difficult skill while the other students needed more assistance. Thus, the school culture of accepting and normalizing differences in ability among the students was reinforced.

In discussing the positive feelings teachers and students had towards Personalized Learning at Thomas Charter School, it is also important to acknowledge other factors that may have contributed to their satisfaction. For example, because the school was a new school, there was a lot of excitement in the community, particularly among parents who wanted to get their children into the school. Due to the high demand, the school had to implement a lottery system to select students. Getting into Thomas Charter School therefore became a privilege for the select few. It is worth pointing out the contradiction between the Personalized
Learning approach of "customizing" education for individual students and the marketization of education that creates competition in access (Campbell et al. 2007).

In terms of students' positive experiences, all students came to Thomas from different schools and were therefore in the same position of being eager to make new friends; it was also a chance for everyone to have a fresh start. In addition, because of the small scale of the school, with only one class per grade, it was very easy to build a sense of community. These situations were particularly meaningful for students who had been bullied at their previous schools. Similarly, teachers who applied to teach at Thomas were actively seeking teaching opportunities in a different school environment, which could in itself have increased their level of contentment in a new school.

The school was not without its challenges of course, some of which were associated with a newly implemented commitment to PL. One of the main challenges teachers faced was associated with giving students so much choice in the classroom. Not only did this require different forms of accountability for work that students completed, it also required having to motivate students to push and challenge themselves beyond the minimum amount of work. The principal noted that some students did not want the freedom that Personalized Learning afforded them. Rather, they wanted to be fully guided and told what to do and how to do things. Teachers also described struggling with the work that Personalized Learning required, notably the challenges in implementing whole-group learning due to the many different levels that students were on. They also described not having enough materials to draw from, particularly for higher level students. These students were often not able to advance because they were waiting for materials. Teachers also discussed the need for improving the communication of student achievement and the standards the students were working on with families. For example, if a student had an A in the class, this did not mean they had an A in sixth-grade standards; they had an $A$ in the standards they personally were working on, which were based on their ability level. 


\section{Conclusion}

Personalized Learning is not an approach to learning that can be easily implemented with the inclusion of student choice, goal setting, and individualizing instruction. Personalized Learning must also involve the development of a school culture that fosters a new mindset about learning for both students and teachers. Students need to acquire a mindset where they take ownership of their learning, challenge themselves, and monitor their progress toward self-made goals. Teachers need to adapt their mindset to be invested in meeting each student at their level, modifying the amount of work for students while also paying attention to standards, addressing students' different ability levels, and guiding students' transition from relying on instruction from the teacher to taking ownership of their learning.

These changes are at the heart of Personalized Learning and have been reported in other research. Campbell et al. (2007) noted in their study of PL in the U.K. that school values were developed around:

learning behaviour, respecting differences in views, taking account of student voice, and the importance of self-motivation for learning. This set of values was the underpinning infrastructure of the personalised pedagogy, and without their influence on the attitudes and behaviour of teachers and students in classrooms it is probable that the pedagogy would collapse. (153)

Although Personalized Learning aligns with the positive outcomes discussed, it is possible that the beneficial outcomes identified in the school are due to underlying factors such as the school culture and organizational structure that both the administration and teachers have committed to, rather than to the implementation of PL itself. Having both the administration and teachers commit to the idea and implementation of PL can most certainly influence the outcomes of the approach. The culture that developed at Thomas Charter School was described as a loving and safe, a place where students were not overlooked. A big emphasis was placed on having fun while learning in order to engage students and promote positive academic and social-emotional development. The students I interviewed credited the school culture at Thomas Charter School as the reason they no longer got bullied and why they looked forward to attending school. They enjoyed school because they had peers who were willing to help them, and they did not struggle academically anymore because they were doing work at their own level and receiving help from their teachers. Overall, it was clear that Personalized Learning involved much more than personalizing instruction for students. It involved creating an entirely new school culture focused on supporting students and cultivating students' academic and social-emotional growth. 


\section{Acknowledgements}

I would personally like to thank Dr. Julia Wilkins, professor of my capstone class, for her constant support and encouragement throughout my research, my fiancé, Chandler Rhodes, for his patience and understanding, and both my parents and sister for their motivation and for coming to my presentation based on this research. 


\section{References}

Bernacki, Matthew L., and Candace Walkington. 2018. "The Role of Situational Interest in Personalized Learning." Journal of Educational Psychology110 (6): 864-881.

Bingham, Andrea J., and Oluwafolakemi Ogunbowo Dimandja. 2017. "Staying on Track: Examining Teachers' Experiences in a Personalized Learning Model." Journal of Ethnographic \& Qualitative Research 12 (2): 75-96.

Bingham, Andrea J., John F. Pane, Elizabeth D. Steiner, and Laura S. Hamilton. 2018. "Ahead of the Curve: Implementation Challenges in Personalized Learning School Models." Educational Policy 32 (3): 454-489.

Campbell, R. J., W. Robinson, J. Neelands, R. Hewston, and L. Mazzoli. 2007. "Personalised Learning: Ambiguities in Theory and Practice." British Journal of Educational Studies 55 (2): 135-154.

Catto, Sarah. Interview with Emily Cowart. August 152019.

Creswell, John W., and Cheryl N. Poth. 2018. Qualitative Inquiry \& Research Design: Choosing Among Five Approaches. Thousand Oaks, CA: SAGE Publications.

DeMink-Carthew, Jessica, Mark W. Olofson, Life LeGeros, Steven Netcoh, and Susan Hennessey. 2017. "An Analysis of Approaches to Goal Setting in Middle Grades Personalized Learning Environments." Research in Middle Level Education Online 40 (10): 1-11.

Denzin, Norman K., and Yvonna S. Lincoln, eds. 2011. The Sage Handbook of Qualitative Research. Thousand Oaks, CA: SAGE Publications.

Lee, Dabae, Yeol Huh, Chun-Yi Lin, and Charles M. Reigeluth. 2018. "Technology Functions for Personalized Learning in Learnercentered Schools." Educational Technology Research \& Development 66 (5): 1269-1302.

Murphy, Marilyn, Sam Redding, and Janet Twyman, eds. 2016. Handbook on Personalized Learning for States, Districts, and Schools. Temple University, Philadelphia, PA: Center on Innovations in Learning. 
Netcoh, Steven. 2017. "Balancing Freedom and Limitations: A Case Study of Choice Provision in a Personalized Learning Class." Teaching and Teacher Education 66: 383-392.

Olofson, Mark W., John M. Downes, Carmen Petrick Smith, Life LeGeros, and Penny A. Bishop. 2018. "An Instrument to Measure Teacher Practices to Support Personalized Learning in the Middle Grades." Research in Middle Level Education Online 41 (7): 1-21.

Patton, Michael Quinn. 1999. “Enhancing the Quality and Credibility of Qualitative Analysis." Health Services Research 34 (5): 11891208.

Pane, John F., Elizabeth D. Steiner, Matthew D. Baird, and Laura S. Hamilton. 2015. “Continued Progress: Promising Evidence on Personalized Learning." Santa Monica, CA: RAND Corporation. https://www.rand.org/pubs/research_reports/RR1365.html.

Schmid, Regina, and Dominik Petko. 2019. "Does the use of Educational Technology in Personalized Learning Environments Correlate with Self-reported Digital Skills and Beliefs of Secondary -School Students?" Computers \& Education 136: 75-86. 